\title{
Emerald $\begin{gathered}\text { Equal Opportunities } \\ \text { International }\end{gathered}$
}

Pleading the Fifth: Refocusing Acker's Gendered Substructure Through the Lens of Organizational Logic

\begin{tabular}{|r|l|}
\hline Journal: & Equal Opportunities International \\
\hline Manuscript ID: & EOI-01-2009-0010.R2 \\
\hline Manuscript Type: & Original Article \\
\hline Keywords: & Gender, Discrimination, Qualitative research, Feminism \\
\hline
\end{tabular}

\section{s ScholarONE" \\ Manuscript Central}




\title{
Pleading the Fifth: Re-Focusing Acker's Gendered Substructure Through the Lens of Organizational Logic
}

\begin{abstract}
In this paper we argue that the (widely recognized) heuristic value of Joan Acker's "gendered substructure" has not been realized due to inconsistencies in its interpretation and application. Through an exploration of the roots of Acker's framework and its application to a case study of a single organization over time (Pan American World Airways), we contend that its greatest potential lies in examining the four process sets - division of labour, workplace culture, social interactions and (self) reflection - through a fifth process of 'organizational logic' that is seen as temporal and contextual. Drawing on poststructuralist feminist theory, we argue that organizational logic can be viewed through analyses of organizational, and organizationally based, discourses.
\end{abstract}

\section{Keywords:}

Acker; Gendered substructure; organizational logic; poststructuralism; feminism 


\section{INTRODUCTION}

The notion of organizations as gendered is not new (Benschop \& Doorewaard, 1998a; Cockburn, 1985; Collinson \& Hearn, 1994; Ferguson, 1984; Mills \& Tancred, 1992). Yet critical gaps in our understanding of the processes responsible for the creation and maintenance of these gendered organizations still exist (Benschop \& Doorewaard, 1998b; D. Britton, 2000; Collinson \& Hearn, 1994). Within the existing breadth and depth of feminist organizational scholarship (Calas \& Smircich, 2006), an increasing number of researchers have been drawn to Joan Acker's (1990, 1992a, 1992b) notion of the "gendered substructure" as one of the more promising frameworks for analysis of the gendering of organizations. However, despite widespread referencing of Acker's framework, ${ }^{\mathrm{i}}$ it has been under-utilized and under-analyzed (D. Britton, 1997; Calas \& Smircich, 2005). In this paper we set out to deal with both issues simultaneously by developing an analysis of Acker's gendered substructure through, and reflection on, its application.

To deal with not only the integrative (i.e., how the gendered processes work together) but also the temporal and contextual aspects of the gendered substructure, analysis is explored through a case study of the gendering of a single organization over time -- Pan American World Airways (Pan Am). The choice of Pan Am owes much to the existence of an extensive archive $\mathrm{i}^{\mathrm{ii}}$ and a number of written histories ${ }^{\mathrm{iii}}$ that allowed us to trace events over time; the gendered character of the airline industry in popular culture (Baker \& Jones, 1967); and opportunity -- we were already involved in a broader study of Pan AM (Mills, 2006).

Our analysis begins by surfacing conflicting understandings of Acker's framework. While a few researchers draw on Acker's (1990) earlier framework of five inter-related processes -- division of labour, workplace culture, social interactions, (self) reflection, and 
organizational logic (see the work of Benschop \& Doorewaard, 1998a), most researchers draw on Acker's later iteration (1992a, 1992b) consisting of four processes - with organizational logic (the fifth process) now missing from the framework. Through an exploration of both versions of the gendered substructure we contend that the notion of organizational logic serves an important integrative function that the later version lacks. Thus, we conclude with a plea for further research and empirical studies based on Acker's original notion of organizational logic as an organizing principle of gendered processes, to address the gendering not only of organizations but also theories of organization.

\section{ACKER THROUGH THE LOOKING GLASS}

Drawing directly on the work of Acker (1990, p.146), we define gendering as, "advantages and disadvantage, exploitation and control, action and emotion, meaning and identity, [that] are patterned through and in terms of distinction between male and female, masculine and feminine," not only at the level of organizational processes and structuration, but also in the way that organizations are defined and conceptualized (Britton, 2000, p.419). It is this latter point that constitutes the notion of an organizational logic, which is missing from subsequent iterations of Acker's framework.

Arguably, while we know much about the gendered outcomes of organizations (Rindfleish \& Sheridan, 2003), we know less about how gendering processes are developed, maintained, and changed over time (Mills, 2006; Townsley, 2003). In this latter regard, Acker's work provides one of the more compelling and "systematic attempt(s)" (Britton, 2000, p.429). 


\section{Acker's Gendering Processes}

Acker (1990) initially identified five general categories of processes that lead to gendered organizations:

- Gendering practices / structures: This process set is first introduced as "the construction of divisions along gender lines" (Acker, 1990, p. 146) and includes the division of labor, behaviors, locations in physical space, and power. In 1992, this same process set is introduced as "the production of gender divisions," and explained as "ordinary organizational practices [that] produce the gender patterning of jobs, wages, and hierarchies, power, and subordination" (Acker, 1992, p.252). What is perhaps crucial to this new definition is the addition of the notion of "practices" that create these gendered divisions. Here, we can start to see what Acker means by processes. That is, merely identifying sex segregation of jobs or "masculine" hierarchies is not entirely helpful. Her new definition encourages us to look at the everyday practices that are responsible for such gendering (i.e., recurring sets of behaviours designed to reproduce a particular end such as ways of recruiting and evaluating employees). In short, processes are now defined in terms of practices and seem to be interchangeable. For consistency, we use Acker's reference to processes when discussing the four or five elements of the gendered substructure.

- Gendering cultures: The "creation of symbols, images, and forms of consciousness that explicate, justify, and, more rarely, oppose gender divisions" (Acker, 1992b, p.253). Evident in our public and private lives, these symbols, images, and forms of consciousness serve to shape societal norms and values. For example, organizational 
symbols and slogans emphasizing strength, speed, or power help to create an environment that values characteristics traditionally associated with "maleness."

- Gendering interactions. The "interactions between individuals, women and men, women and women, men and men, in the multiplicity of forms that enact dominance and subordination and create alliances and exclusions. In these interactions, at various levels of hierarchy, policies that create divisions are developed and images of gender are created and affirmed" (Acker, 1992b, p. 253). Acker uses conversation analysis to demonstrate that turn taking, interruptions, and topic setting can be studied to demonstrate the gendered nature of ordinary talk.

- Internal gender constructions. The "internal mental work of individuals as they consciously construct their understandings of the organization's gendered structure of work and opportunity and the demands for gender-appropriate behaviors and attitudes" (Acker, 1992b, p. 253). It is evident that Acker intends the set to look at how individuals navigate their gendered identities within organizations and that this navigation is guided by expectations of how one ought to look and behave, the rules of which are assigned by sex.

- Creating and conceptualizing social structures. The final set of processes, and the one that disappeared -- in its specific form -- from subsequent iterations, is centered on organizational logic and the gendered substructures that are reproduced in daily organizational activities and the writings of organizational theorists (Acker, 1990). We note here that there are at least three potential levels implied in the term organizational logic; i) a dominant set of ideas about organization that is produced through an iterative process of management practice and organizational theories of those practices (Clegg, 
1981) that are located in broad socio-economic phenomena (e.g., the interplay between work and domestic life - Acker, 1992b); ii) a dominant set of structures and processes that come to characterize organizational arrangements, which are, iii) manifest in "material forms in written work rules, labor contracts, managerial directives, and other documentary tools for running large organizations" (Acker, 1990, p. 147). Acker (1992b, p.255) captures all three levels where she argues that the "gendered substructure lies in the spatial and temporal arrangements of work, in the rules prescribing workplace behaviour, and in the relations linking workplaces to living places. These practices and relations, encoded in arrangements and rules, are supported by assumptions that work is separate from the rest of life and that it has first claim on the worker" and these assumptions have become normalized through theories of organization that view organizational arrangements as gender neutral." Ironically, this key statement appears in a discussion of the later, four processes version of the gender substructure and, while it signals the integrative potential of a logic of organization, its wider heuristic value is lost.

\section{Building on Acker}

Acker's $(1990,1992 b)$ framework of gendering processes has been widely cited throughout the feminist and organization literatures. Nonetheless, it has rarely been applied (Brewis, Hampton, \& Linstead, 1997; Maddock, 2002), and only partially so in the majority of cases (D. Britton, 1997; Olsson \& Walker, 2003). Little has been done empirically to support or refute the significance of the proposed processes as a set (Britton, 1997, 2000), though several studies have identified the presence and impact of individual processes (Hultin \& Szulkin, 2003; Rutherford, 2001). Even here most accounts have only focused on Acker's notion of "gendering 
practices/structures" and, to a lesser extent, "gendering [organizational] cultures." There have been few attempts to address "gendering interactions" or "internal gender constructions" and the fifth process (“creating and conceptualizing social structures") has been largely overlooked (Dye \& Helms Mills, 2005), which is hardly surprising given the fact the Acker did not include it in her subsequent discussions of the gendered substructure. Even fewer studies have looked at multiple sets of processes from Acker's framework (for exceptions see Britton, 1997; Benschop \& Doorewaard, 1998b; Lewis \& Morgan, 1994) and fewer still, have done so using Acker's framework in its entirety (see Benschop and Doorewaard,1998a, 1998b).

Although, Acker "problematizes the processes as distinct and separate catalysts for the 'gendering of organizations"” (Dye \& Helms Mills, 2005, p.5), she acknowledges that the processes interact and are, in practice, "parts of the same reality" (Acker, 1990, p.146). As has been argued elsewhere (Dye and Helms Mills, 2005; Benschop and Doorewaard, 1998a), gendering processes do not exist in silos and are likely more interdependent than typically credited. As such, it is perhaps more useful to look at the dynamics of and between the five sets of gendering processes. We would also argue that these dynamics should be studied in context and over time because, although implicit (culture, for example, implies a processes that has developed over time), it is underdeveloped in Acker's framework. We would argue that "to understand the gendered subjectivities of the actors involved we need to understand the discourses in which they were located and the relationships in which they were involved" (Mills, 2002, p.300). Acker's framework provides the opportunity to study gendered processes within context. That is, the multiple levels of analysis afforded by Acker's heuristic has the potential to encourage the researcher to seek out much needed information about dominant discourses, relationships, internal gender constructions, and organizational logics of the time. 


\section{EXPLORING GENDERED PROCESSES AT WORK: PAN AMERICAN AIRLINES OVER TIME}

Our way of exploring the value of Acker's framework was to attempt to apply it, simultaneously probing the theoretical issues involved and their application (e.g., what is meant by "processes" and how can they be studied?). Given the assumed character of the 'gendered substructure,' as an interrelated set of processes in a specific organizational context, we adopted a case study research strategy that would allow us to focus "on the interrelationships that constitute the context of a specific entity [viz. the gendered substructure; analyze] . . the relationship between the contextual factors and the entity being studied [viz. the relationship between organizational logic and the other elements of the gendered substructure; and use] . . . those insights ... to generate theory and/or contribute to extant theory [viz. Acker's theoretical framework]" (Mills, Durepos, \& Wiebe, 2009, introduction).

Our choice of an organization to study relied on several factors, not least of which was the extent to which Acker's framework can deal with change (e.g., can gendered substructures be changed and what are the implications for addressing workplace discrimination?). This is a critical issue because Acker's work, while focused on challenging the viability and existence of the gendered substructure, has sometimes suggested, "it is possible to see how integral to modern organization this gendered substructure is, and how relatively inaccessible to change it remains" (Acker, 1992b, p.255). For us, the potential value of Acker's framework lies in an ability to identify factors of change. Otherwise, it is reduced to a more-or-less confirmatory approach that is developed through descriptive evidence of each set of processes.

Our focus on change led us to look for an organization that we could study over time, searching for evidence of a gendered substructure at different points of time, comparing their 
character (e.g., outcomes for female employees), and analyzing the different contexts for clues to the specific dynamics of the change (e.g., what led to changes in the way women and men were imaged and employed, what are the implications for the people involved, and what does this tell us about the viability of Acker's framework).

The organization we chose to study was Pan American World Airways (Pan Am) because of a wealth of archival materials and written histories on the company that facilitated study over time; the fact that the company was well known, having occupied a central position in United States aviation from 1927 to 1991; because it was part of an industry known for its popular culture iconic images of gender, e.g., the 'sexy' flight attendant; the 'heroic' pilot (Baker \& Jones, 1967; Kane, 1974); and, through opportunity - Pan Am was already part of a broader study within which we were involved (second author, 2006). A variety of corporate documents were used in the analysis. However, the following in-house magazines proved invaluable to the research process and served as the basis for much of the analysis: Pan American Airways, New Horizons, Clipper News, and Sales Clipper. These publications were written by and for Pan Am employees.

The first part of the study involved the selection of two periods in time that were (a) sufficiently different in terms of the employment and imaging of women and (b) consisted of sufficient materials and other artifacts to facilitate the study. In regard to the latter criteria, due to a relative lack of archival material, we eliminated the period from the founding of Pan Am in 1927 to the onset of America's entry into World War II in 1941. We also eliminated the war years (1941-45) because of the unique circumstances surrounding changes in the airline's employment (with the percentage of female employees rising to 35\%). The two periods we settled on were: a period from the late 1940s to the end of the 1950s when, immediately 
following the post-war downsizing of female labour, women became seen as a 'normal' but temporary part of the airline; and the late 1970 s to the end of the 1980 s when women were being employed to supervisory, professional, and middle managerial positions in increasing numbers. For the sake of simplicity we refer to these periods as the 1950s and 1980s.

Having established these time periods, the second part of the study involved attempting to apply Acker's five gendered processes to each time frame. This involved sifting through extensive archival materials for evidence of each of the five processes, making assessments of the problems involved in attempting to surface each process and find convincing evidence of their inter-relationships sufficient to constitute a gendered substructure.

Our 'reading' of the archival materials was informed by a combination of feminist poststructuralism (Weedon, 1993), critical discourse analysis (Phillips \& Hardy, 2002) and critical hermeneutics (Prasad \& Mir, 2002). What this means in effect is that, as feminist poststructuralists, we are interested in the way women and men are socially constructed through discursive practices (i.e., the development of influential ideas in and through practices that are mutually reinforcing), such as employment policies (e.g., the relative job positions of men and women) and corporate imagery (e.g., the depiction of women and men in various corporate documents, including annual reports, advertisements, in-house newsletters, histories). Here we collected details of women's and men's employment rates and job categories, as well as the use of written (e.g., stories, reports) and visual (cartoons, photographs) text to discuss men and women in direct and indirect ways.

We viewed our reading of the archival material as textual interpretation and used critical hermeneutics as a way of problematizing both text and interpretation. From this approach we sought to understand various texts not only from the intent of the author but more so from the 
socio-political context in which it was written and, in the process of research, potentially "hidden meanings that serve the interest of the socially and politically powerful" (Prasad \& Mir, 2002, p.96). In other words, we not only searched for the more obvious references to women's and men's positions in the airline but also those that privileged masculinity or femininity without necessarily directly referencing men and women (e.g., discussion of the physical strength or emotional stability required to do certain jobs that are 'normally' associated with one sex or another). Critical hermeneutics also reminds us that the reading of any text is problematic in its interpretation and has to be treated with some caution. Thus, we are reminded that the texts we examined were all written for a range of purposes, almost never as justification of, or intent to, discriminate. That is why we treat text not from the intentionality of the author so much as a reflection of and contribution to on-going cultural notions of gendered differences. While the texts we studied almost certainly had some influence on gendered ideas, the extent of the influence is more speculative, and a reading of the context is all-important because of shifts in meaning. Nonetheless, with that caveat, we would argue that the sheer range and number of materials that we examined provides a plausible account of the influence of Pan Am's corporate communications (coupled with hiring practices) on dominant images of men and women in the company at given points of time.

To understand how individual ideas (e.g., those expressed in an editorial) may contribute to widely held views of men and women (e.g., the idea that women do not make good pilots) we drew on critical discourse analysis (Phillips \& Hardy, 2003). We also saw this as being true to Acker's notion of 'organizational logic,' with its implied sense of mutually reinforcing ideas and practices that run through organizational behaviour. Here, against a background study of the workplace division of labour and imaging of men and women, we set out to explore the extent to 
which recurring themes, narratives and stories were evident across a range of viewpoints and practices. We were interested to see not only how men and women were characterized over time but also whether there were differences over time and the implications for the notion of a gendered structure.

\section{MAKING SENSE OF THE DATA}

The process of analysis began with an exploration of the various data for 'evidence' of Acker's gendering processes. This was relatively unproblematic for the first two sets of processes as the data fell quite nicely into the categories determined by Acker. Evidence of gendered practices for example, could be found in a number of work practices and hiring polices which clearly delineated between men's and women's work. Similarly, there were numerous signs of cultural practices, such as beauty pageants for example, that evidenced cultural influences on the presentation of women and of men. The remaining three processes proved more difficult to deal with.

'Evidence' of gendered interactions presented us with our first problem in applying/ developing Acker's heuristic. The implication is that these could/should be accessed by way of observational and conversational techniques. This is clearly possible for contemporary studies but presents a challenge for archival studies such as ours. We dealt with the problem through a focus on textual and visual attempts to represent gendered interactions, through such things as internal newsletter discussions, editorials, letters about gender differences, and cartoons that often depicted gendered relationships (e.g., amorous male bosses and sexually acquiescent female secretaries). Here we were looking for examples of different messages addressed to specific audiences that evidenced men talking to men (e.g., articles about piloting by male pilots 
who assume they were talking directly to other male pilots); women talking to women (e.g., articles by female beauticians telling women how to apply cosmetics - there were such artifacts!); and women talking to men (e.g., letters of complaint from female employees to assumed male managers).

When it came to identifying evidence of "internal gender construction," we confronted our second problematic in applying Acker's framework, namely, how do you see into the minds of people as they make sense of realities and construct their gendered identities? Drawing on Helms Mills' (2003) analysis of sensemaking and identity construction, we examined texts that voiced some opinion on gender but which were not clearly designed for corporate ends, i.e., we looked at items in the in-house newsletters (rather than in annual reports and advertisements). In short, we examined certain gendered commentary for signs of how the author was positioning their own gendered identity.

The final set of processes, "creating and conceptualizing social structures," was at once difficult and easy to see. Acker first introduces us to the concept as an organizational logic that can be determined by corporate rules, policies and procedures. This is easily identified through examples of procedures that clearly favoured one sex over another. However, elsewhere, Acker speaks of this same process set as more of a gendered substructure which "links the more surface gender arrangements with the gender relations in other parts of the society" (Acker, 1992b, p. 259). This was much more difficult to apply using this surface level approach and presented yet another potential problem with the application of Acker's framework in this manner. Here we set out to find themes, stories and narratives about the organization (Pan Am) in particular, and organization in general. This was where we were looking for evidence of discursive practices 
that appeared to constitute a deeply structured notion of what a 'normal' organization looked like (e.g., the naturalization of hierarchy through the use of organization charts).

Throughout the process we collected various data and accompanying field notes where we reflected on aspects of the data. At the end of this exercise, we ended up with an 'inventory' of 'evidence' of Acker's gendering processes, but were left feeling that the framework, used in this way, lends itself to simplistic, surface- level analysis. What were needed were not only rich descriptions but also a way of making sense of the descriptions such that they would provide an overall picture of the gendered experience. Indeed, the exploration created more questions than answers, including questions about the inclusion, interpretation, and application of the fifth set of processes and its relationship to the other processes. We also wondered about the relationship between the process sets, and the extent to which the overall framework is a useful heuristic for identifying change strategies. This led us to a closer examination of the role of discourse and time.

Through a re-reading of the field notes and archival material at a much more "removed" level, and jotting down single words and phrases that seemed to capture the essence of what was being read at a selected period in time, it became apparent that almost everything, from rules and regulations to slogans and nicknames, was related to dominant notions of men and women. As we critically analysed texts for the selected comparable periods it became evident that not only were different discourses at play but also that they served to make sense of the interplay between the various gendered processes.

\section{The Dominant Discourse in the `1950s’}


Pan Am in the 1950s was very much about the traditional 'family.' Characterized by words to the effect that "we're all in this together" and descriptions of the workforce as "one big happy family", employees even referred to each other as "brothers" and "sisters". The metaphor permeated much of the organization's corporate communications. Employees were "Members of [the Pan Am] Family" (Pan Am Clipper, 1953a, p.5), with senior men often cast as father figures or "head(s) of the [Pan Am] household." Younger men were often characterized as sons who needed to focus on establishing their career before being "caught" by a woman for marriage or to be wary of beautiful women "putting the jinx on" them (Pan Am Clipper, 1956c, p.5). The married employees, on the other hand, were described as having wives who were long suffering, persevering in the face of adversity, and always willing to serve with a smile. Female employees were characterized as mothers/wives, daughters, or mistresses. Their roles within Pan Am were characterized by domesticity, servitude, and pleasant efficiency. For example, "flight stewardesses" were expected to be "gracious" hostesses, "alertly anticipating her passengers' needs and providing the necessary services in an attractive and efficient manner" (Pan American Airways, 1956e, p.6). Other members of an employee's family were also co-opted into the family story with, for example, newborn babies being referred to as "baby stewardesses" and "baby stewards" (Pan Am Clipper, 1956a, p.2). The newsletters also offered advice to family members, such as "wife saving” techniques (Pan Am Clipper, 1954a, p.9).

\section{Acker and the Discourse of Family}

Beyond the obvious link of gender, we initially had some difficulty gaining a sense of what served to integrate the various processes of Acker's framework. However, the more we probed for themes, narratives and stories the more we realized that a strong discourse of family - 
in particular the traditional nuclear family image that dominated the United States in the 1950s (May, 1989) - permeated the organization. We believe that this discourse of family may help to explain not only how the various aspects of the gendered substructure are integrated (i.e. through the discourse) but also how an underlying logic of organization is reproduced through gendered practices (although not necessarily gendered practices alone). In essence, the discourse of family provides the 'logic' through which the organization is structured, and policies and practices are established. This 'logic' serves as the guide for sensemaking (Weick, 1995) in the organization and, in turn, is reproduced through gendered practices. Space permits only a glimpse of the myriad of materials that illustrate the associations between the family discourse and each of Acker's processes.

Gendering practices/structures. At the most basic level, one can see the gendered divisions at PAA in terms of numbers. Men dominated the industry, including the senior, professional and skilled positions. Women were mostly employed in secretarial and support roles. It is in the various explanations of these divisions that we see references to gendered notions of the family and the respective roles of men and women. This appears in a number of guises, including a continual stress on women's temporary role in the workplace (e.g., innumerable comments about how the company 'loses' female employees to marriage) in contrast with men's careers; and the continual characterization of women's work as an extension of domestic duties. As the following example demonstrates, even where women do achieve longterm status with the company her status is portrayed as one of service to male bosses:

"Mrs. Dorothy Ford Davies Becomes First of Fair Sex at Miami to Get 25-Year Pin.

A lady who has spent 25 years in the same department and a couple of gentlemen 
who have filled [Pan Am] posts from Rio de Janeiro to Alaska are among the latest veterans to join [the airlines'] Quarter Century Club” (Pan Am LAD Clipper, 1954, 11/9, p.3).

The next extract clearly demonstrates the rhetoric of family in characterizing women's work: under the headline "Housecleaning Daily Chore for Pan American Clippers" the reader is informed that stewardesses comes on board and check on "all the things a woman needs to run a home or an airliner" (Pan Am Clipper, 1956g, p.7).

Gendering cultures. The notion of women as temporary employees on their way to marriage and domesticity was reinforced through innumerable cultural artifacts, including emphasis on the youth and beauty of unmarried female employees; grooming classes for younger women; regular articles on the looks and marriageability of selected women; and celebrations of engagements, marriages and births. Company organized beauty pageants proliferated in this period; newsletters contained regular features on employee marriages and birth; and the in-house Clipper featured "Clipper Cuties," that characterized much of the celebration of sexuality within the airline, with the "cuties" described in terms of their physical characteristics, with "curves in the right places" (Pan Am Clipper, 1956h, p.3). A contrasting focus on "The Man of the Month," described male employees in terms of their skills, abilities and experience. Even in areas described as "training" the family theme was embedded in such things as a women-only "Look as Smart as You Are" program of "grooming and manners" (Pan Am Clipper, 1955b, p.3). Men, on the other hand, were offered "Management Training" through a program of "study" (Pan Am Clipper, 1952, p.3).

Gendering interactions. A central depiction of male-female relationships is the bosssecretary relationship, which seems to stand in for the ideal-typical gender relationship. In 
cartoons, for example, women are depicted as subordinate to men not only in employment terms but also in sexual terms. An example of the latter is a cartoon depiction of a secretary sitting on her boss's lap, saying, "I like this work much better than filing, Mr. Higgins. I'm not on my feet so much" (Pan Am Clipper, 1956i, p.2) but perhaps the classic conflation of work with the domestic relations is a cartoon of a bride and groom leaving the church and the husband saying, "We'll have to hurry back to the office dear. I want you to take a few letters" (Pan Am Clipper, 1954b, p.6).

Internal gender constructions. In commentary on gendered behaviour one of the more prominent expressions was the view that masculinity was associated with career, and femininity with marriage and children (rather than work). It was quite commonplace to report such things as, "Jean Stoecker ... has left [the airline] for wedding bells and southern belle living in Georgia" (Pan Am Clipper, 1956b, p.3), and "Although Rosemary now has a beautiful apartment, in addition to a husband, she will continue to work for the company for a while" (Pan An Clipper, 1956d, p.2). Masculinity was usually linked to skill, expertise and the physical strength of male workers, as in the following comment: "The Cargo department no longer needs any forklifts. Our two new Cargo reps [...] are of such dimensions that they can load and unload [...] without any technical help" (Pan Am Clipper, 1956i, p.2). As the following example indicates, it was often made clear that such "dimensions" were not normally associated with women: in a cartoon that featured a very large, physically 'unattractive' woman, a male pilot is shown saying to a colleague, "She wants a job as a stewardess ... says she is not likely to leave to get married" (Pan Am Clipper, 1953b, p.1).

Creating and conceptualizing social structures. Very often, the rules, policies and procedures at Pan Am, subtly but effectively established who belongs where. An underlying 
assumption throughout was that the employee would be male, because "a dependent, as far as this policy goes, can be a wife or a child - never a husband - even tho she may buy the old boy a beer now and then" (Pan Am Clipper, 1954b, p.1).

Recruitment policies and job procedures were particularly powerful in determining who belonged at Pan Am. They reinforced the sex segregation of jobs, the gendered work culture, and the identity construction of employees. The job requirement for stewardesses, for example, overlooked nothing - age (“21-27 years old”), vision (“20/20”), height (5'3” to 5' 7”), weight ("in proportion to height"), education ("minimum of high school"), physical looks ("glamorous"), marital status (single), and personality requirements ("gracious") were all outlined (Pan Am Clipper, 1956j, p.6). This differed from the requirements for stewards who, at the time of recruitment, could be married, and as old as thirty-five (Pan Am Clipper, 1951, p.1). Here, arguably, we can see a link between the rules and procedures as manifestations of an organizational logic infused with/informed by a discourse of the traditional American family of the 1950 s.

\section{Pan Am in the ‘1980s’ - The Dueling Discourses}

As we set out to compare the 1950 s with the later period it became increasingly clear that not only had a new dominant discourse - competition - arisen as an organizing principle for gendered interactions but that there was also a competing - women's liberation - discourse vying for attention.

The discourse of competition. Work in the North American airline industry during this time looked much different than it did in the 1950s. Unionization, the women's liberation movement (Oakley, 2002; Walters, 2005), affirmative action initiatives (Appelbaum \& Batt, 
1994), anti-equity litigation (Skoppek, 1989), and airline deregulation (Bender \& Altschul, 1982), were all having a significant impact on the nature of airline work - creating a more adversarial and competitive work environment.

As we looked closely at discussions of employment at this point we detected a strong theme of competition that permeated airline talk and served as a form of organizing logic in the making of hiring decisions and in the making of the ideal-typical employee. In general terms, as airlines competed for passengers, corporate concerns evolved around efficiency, rationality, productivity and the bottom line. A discourse of competitiveness can be detected at all levels of the 'gendered sub-structure' and the use of it as an 'organizing logic' that serves to integrate the process sets is also evident.

Gendering practices/structures. There was clearly a gendered division of labour throughout this period. Women still held a tiny minority in the key areas of flight crew, management and piloting, and constituted the greater majority of flight attendants and secretarial roles. However, unlike the previous era, women were now shown throughout corporate materials as a 'normal' part of a range of different work groups, including sales, flight service crew, fleet services, baggage handling, and middle management.

Gendering cultures. While some of the trappings of the old gendered culture remained (e.g., beauty pageants) they were pushed into the background, to be replaced by new foci on efficiency and team work that simultaneously highlighted gender neutrality and women's abilities. Reflecting the new culture, the Pan Am newsletters changed drastically, cutting out cartoons and gossip columns and disparaging the old ways: now reports of staff birthdays was "Ho-hum. Anniversaries? Too numerous to list. Weddings? A church full. Births? Just a few (thank heaven) - and only when they couldn't be helped" (Pan Am Clipper, 1982a, p.8). Instead, 
pages were filled with relatively serious employee profiles, operating statistics, directives from above, and news stories about legislative and policy changes that impacted all Pan Am employees. The new tone was expressed in a letter to the "DEAR FELLOW EMPLOYEE: Obviously, if we perform poorly for the customer, he has a number of other airlines to select from" (Pan Am Clipper, 1981a, p.1 - capitals in the original).

Gendering interactions. Much of the depiction of women and men at this point was as disembodied employees, as the airline attempted to deal with efficiencies and perceptions of inequitable practices. Commentary on secretaries, for example, took on a new tone. Although still an all-female position, the secretary was now imaged as a professional "who helps keep her boss, and the department on track," through hard work, "skill, competence and efficiency" which was in large part at the heart of "successful projects" (Pan Am Clipper, 1989c, pp.4-7).

Internal gender constructions. With much of the focus on efficiencies and productivity in the face of stiff competition, discussion of women's abilities moved away from domestic chores to capture the changing workforce of the company as increasing numbers of women moved into a range of hitherto male jobs. Secretaries, as we saw above, were now described in terms of their skills and work ethic. Even physical strength, once the exclusive domain of Pan Am men, was now used to explain women's presence in certain jobs: "It's a Woman's Touch for JFK Fleet Service - it takes brains and brawn, but ten women of varied ages and backgrounds are equal to the task [of] loading aircraft, operating forklifts or skimming across the runway at the helm of a baggage tug [...], doing what used to be called a man's job" (Pan Am Clipper, 1980e, p.7).

The discourse of women's liberation: Alongside the dominant discourse of competition there was evidence of a number of potentially competing, albeit less influential, discourses, 
including community service and volunteering, environment, safety, and women's liberation. The latter discourse, however, was far more evident throughout Pan Am's corporate materials, and so much so that is was invoked almost every time the company referred to female employees. Often co-opted into the discourse of competition through equal opportunity hiring claims, the discourse of women's liberation could be seen through subtle and more overt forms of resistance.

While in the past the gendered division of labour was explained away through reference to women's essential domestic character, now efforts were made to explain inequities in terms of competitive abilities: "Pan Am's interests are served by making certain that its most talented people, regardless of sex, have the opportunity to put their full talents to work in the service of the company" (Rogalin, 1975). The organization's culture of the 1970s included a President's Committee on Equal Employment Opportunity, Women's Opportunities Council, and a series of associated information and discussion events. However, in the gendered interactions to these and other issues, men were sometimes seen as ignoring the issues by female employees, and women were sometimes viewed by senior male managers as simply "letting off steam" (Pan Am Clipper, 1974h, p.17). Expressions of the internal gender constructions of senior male managers often linked gender and business in ways that privileged masculinity. For example, references to 'hiring the best people regardless of sex' can be read as a commitment to the hiring of more women but also a justification for the dominance of male employees. And various references to “improving job opportunities for women . . . because it's good business and a sensible use of valuable personnel resources" (Pan Am Clipper, 1974g, p.24) says as much about the male commentator's business acumen as the company's commitment to greater equity. 


\section{DISCUSSION}

As we argued earlier, there is considerable published work on each of the first three and, to a lesser extent, the latter two, of Acker's gendering processes. However, in attempting to apply Acker's notion of the gendered substructure to our case study of PAA, the overwhelming thing that struck us was that it only really works as a heuristic when, as Acker intended, the constituent elements are viewed holistically as a series of inter-related elements. Applied individually, the five elements do little more than provide descriptive accounts of certain aspects of gendered organizational life. This was certainly true of the PAA study and was particularly evident within gendered practices, policies, and structures and less so within organizational logic. Nonetheless, each element could be seen as an abstraction of the greater dynamic called the gendered substructure. By refocusing on the holistic character of the gendered substructure we turned our attention to the role of each element in the overall process.

Gendering practices / policies / structures. We would argue that this set of factors serves to provide a descriptive account of the pre-cognitive landscape in which ideas are enacted and contested. In other words, practices, policies and structures are a series of artifacts that constitute the context in which ideas are formulated and contested. Conceptually these constitute the enactive environment and sensemaking cues (Weick, 1995) that influence and enable action but do not include the interactions and internal thoughts that serve to develop, maintain, or change their gendered character. To that end, we include policies, practices, informal rules (Mills \& Murgatroyd, 1991), and the use of physical space under this category but each needs to be carefully delineated.

In terms of policies, we agree with Acker's (1992) later iteration where she views policies as aligned with structures and practices rather than as outcomes of organizational logic 
(Acker, 1990). Policies are artifacts waiting to be enacted through gendered interactions. Similarly, the use of space, dropped from Acker's (1990) original list, can be seen as an important gendered cue that signals the relative importance of women and men at work. The notion of practices, on the other hand, speaks to the articulation, rather than simply the existence, of contextual cues. We include it here as cultural traces of recurring events that always 'exist' in some sense prior to new iterations. The same is true of informal rules (Mills \& Murgatroyd), which include those expectations that exist as cultural traces waiting to be re-enacted.

The conceptualization of this set of elements as contextual artifacts is not to assume that they have an objective life of their own or that sensemaking is not 'on-going' (Weick, 1995). Rather it is designed to draw attention to the space between sensemaking cues and enactment (Weick, 1995) that lead to reenactment, or contestation, of gendered realities. It is to ask, what gendered structures exist and how are they developed, maintained and/or changed? To answer this question we need to integrate the other elements of the gendered substructure.

Gendering cultures. Acker recognizes that other, broader contextual dynamics are at play in the construction of gender at work and looks at the impact of organizational culture. Again our attention is drawn to artifacts such as symbols, images, and forms of consciousness, which serve to "explicate, justify, and, more rarely, oppose gender divisions" (Acker, 1992b, p.253). Moving beyond cues as to the gendered character of specific jobs (e.g., pilots are men, flight attendants are women), these `cultural' artifacts shape broader understandings of masculinity and femininity at work (e.g., clues to the relative abilities of men and women that explain why a certain type of masculinity is need to fly a plane and of femininity to serve on a plane). Reference to "forms of consciousness" is, however, problematic both conceptually and methodologically (e.g., how can we observe consciousness?). 
Conceptually, as an artifact, or mechanism, that shapes interactions and thought processes, it would need to focus on the forms through which gendered consciousnesses are expressed. Acker (1992b, p.253) says as much when she references such things as dominant "metaphors of masculinity." This could include available patterns (e.g., metaphors, similes) and styles of speech (e.g., polite versus aggressive discourse) as well as speech forums (e.g., Pan Am's Women's Opportunities Council). Methodologically, the forms of consciousness can be explored through content analysis (Bryman \& Bell, 2007) of recurring types of metaphors, descriptions, and narratives.

So far we have examined issues of context but not those areas of translation where precognitive environments are transformed into enactive environments (Weick, 1995). It is through the three strands of organizational logic, gendered interactions, and internal gendering that the transformation takes shape and either reproduces or changes the gendered substructure of organizations.

Organizational logic. We begin with organizational logic because it forms an overarching formative context (Unger, 2004) in which organizational realities are played out. It is not coincidental that we position it between organizational contexts and agency. We see it as a key bridging explanation that links organizational practices with broad social practices.

The problem, as we noted above, is that Acker provides not only differing accounts of organizational logic but also of its existence as part of the overall framework. For example, her 1990 discussion of the gendered substructure includes "organizational logic" as the fifth set of processes, which is manifest in rules, work contracts, managerial directives, and other workplace practices. In her 1992 iterations, organizational logic is not part of the four processes outlined but she describes the gendered substructure as being linked "to living places" (i.e., families) (Acker, 
1992b, p. 255). In one of her more recent works, Acker talks about substructure as, "practices, arrangements, and ideologies that organize the broad parameters of daily life" (Joan Acker, 2006, p.86). Nonetheless, as has been noted elsewhere (Benschop and Doorewaard, 1998; Britton, 1997), we can detect, across Acker's various accounts, an argument for locating the gendered substructure within broader social processes. ${ }^{\text {iv }}$

What is less clear is what constitutes organizational logic and how it informs the gendered substructure. Earlier we identified three potential (possibly inter-related) elements theories of organization in practice; dominant structures and practices that are iteratively linked to management theory and practice; and the manifestation of theories of organization that run through/are embedded in organizational rules, and constitute the underlying gendered assumptions inherent in the notions of "job" and "worker." Arguably, it is some form of organizational logic that serves to integrate the different elements of the gendered substructure into "coherent arrangements" of structure, culture, interactions, and identity (Benschop \& Doorewaard, 1998).

Leaving aside for now some of the unanswered questions about the character and contours of organizational logic, we may wonder how such broadly based processes come to inform (or constitute) the gendered substructure. Benschop \& Doorewaard (1998, p.789) talk about a "gender subtext" or "the opaque, power-based processes that systematically (re)produce the gender distinction via a set of arrangements," arguing that "the duality of gender - the simultaneous existence of the practices of gender inequality and the impression of equality stems from the structural arrangement of job and task design, is reinforced by organizational culture, sustained by interaction patterns and is deep-rooted in the identities of organization members" (p. 800-801). Yet this still does not help us understand how processes of 
reinforcement (and resistance) occur. We are still left with the idea that gendered substructures are outcomes of structural arrangements. With that in mind, we were drawn to poststructuralist notions of discourse (Phillips \& Hardy, 2002; Weedon, 1993) as a way of explaining the translation of social phenomena into gendered practices.

Through exploration of consistent themes running through the gendered processes we were able to develop a plausible account (Weick, 1995) that linked broad discourses of domesticity, competition, and women's liberation to organizational sensemaking. To that end, discourse can be seen as a bridge between organizational logic and agency.

Gendering interactions. This is the point where Acker introduces the processes whereby contextual factors (structure, culture, organizational logic) are translated into an enacted sense of the organization. She does this through a focus on various interactions between people. However, we don't get a sense of the link between the interactions and the translation process. Indeed, at times we get the impression that gendered interactions are so heavily contextualized as to be overly determined. What is needed here, we contend, are ways of understanding the processes (e.g., sensemaking - Weick, 1995) and strategies (e.g., the use of rhetoric) involved in translating events into plausible accounts (Mills \& Helms Mills, 2004). Again we suggest that discourse analysis can be a useful method for tracing connections and disconnections between ideas and practices that may lead to either reproduction or contestation (e.g., as we saw with the challenge of women's liberation in Pan Am in the 1980s).

Internal gender constructions. Once again this element presents conceptual and methodological challenges. From Acker's various descriptions, she has in mind a form of subjectivity that is linked to but separate from gendered interactions. Acker's (1992b, 253) description of the "mental work of individuals as they consciously construct their 
understandings" of the gendered character of organizational opportunities, structures, and related gender-appropriate behaviors and attitudes, suggests a form of agency that is somewhere between Weick's (1995) individual sensemaker and Foucault's (1980) subject position. Both Weickian and Foucauldian approaches shaped our approach to this area, with a focus on individual identity work (through expressions of powerful individuals) and its contribution and relation to dominant discourses. In that way we could track the way that identity construction contributes to the reproduction or contestation of the gendered substructure.

\section{CONCLUSION}

Our research reinforces the idea that the gendered sub-structure should be viewed, as Acker $(1990,1992)$ intended, as an interrelated set of practices. However, we contend that a more clearly delineated and restored notion of organizational logic is important to make sense of the interrelationships that constitute a gendered substructure. Here we suggest that a more explicit focus on discourse (Foucault, 1980; Phillips \& Hardy, 2003 Weedon, 1993) adds to Acker's notion of organizational logic by providing a way of understanding how the organizational logic of the day (Joan Acker, 2006) comes to inform the production and reproduction of gendered substructures. By tracing changes in dominant forms of discourse over time (e.g., domesticity to competition and women's liberation), we can also address Acker's own concern that the notion of the gendered substructure not be taken as an "essentialized, ahistorical argument that organizations inherently create gender divisions" (Joan Acker, 1998, p.198).

We conclude that Joan Acker's initial conceptualization is important and of significant value. However, some would argue it isn't finished and many would agree that it was never fully appreciated. Through a refocus on the fifth process, we believe that Acker's framework can 
be used to explore not only the ways in which organizations are gendered, but also how they become gendered and how gendered processes change overtime. It provides an invaluable way of destabilizing truths and encouraging the opening of new discursive spaces where gendering can be challenged (Ferguson, 1984; Mills \& Chiaramonte, 1991).

This research is by no means over. A renewed focus on organizational logic (the fifth process set) is only the beginning of a worthwhile journey and a number of issues that are beyond the scope and space of a single paper need to be reviewed, not least of which is further delineation of the notion of organizational logic, issues of power (Benschop and Doorewaard, 1998), and sexuality (Joan Acker \& van Houten, 1974; McDowell \& Court, 1994). 


\section{REFERENCES}

Acker, J. (1990) Hierarchies, jobs, bodies: A theory of gendered organizations. Gender \& Society, 4, 139-158.

Acker, J. (1992a) From Sex Roles to Gendered Institutions. Contemporary Sociology, 21(5), 565-569.

Acker, J. (1992b) Gendering Organizational Theory. In A. J. Mills \& P. Tancred (eds.), Gendering Organizational Analysis. Newbury Park, CA: Sage.

Acker, J. (1998) The future of 'Gender and Organizations': Connections and boundaries. . Gender, Work \& Organization, 5(4), 195-206.

Acker, J. (2006) Class Questions: Feminist Answers. Maryland: Rowman \& Littlefield Publishers, Inc.

Acker, J., \& van Houten, D. R. (1974) Differential recruitment and control: the sex structuring of organizations. Administrative Science Quarterly, 9(2), 152-163.

Appelbaum, E., \& Batt, R. (1994) The New American Workplace: Transforming Work Systems in the United States Ithaca, NY: ILR Press Books.

Baker, T., \& Jones, R. (1967) Coffee, Tea or Me? The uninhibited Memoirs of Two Airline Stewardesses: Bartholomew House.

Bender, M., \& Altschul, S. (1982) The Chosen Instrument. Juan Trippe. Pan Am. The rise and fall of an American entrepreneur. New York: Simon \& Schuster.

Benschop, Y., \& Doorewaard, H. (1998a) Covered by equality: The gender subtext of organizations. Organisation Studies, 19(5), 787-805.

Benschop, Y., \& Doorewaard, H. (1998b) Six of One and Half a Dozen of the Other: The Gender Subtext of Taylorism and Team-based Work. Gender, Work and Organization, 5(1), 5-18.

Brewis, J., Hampton, M., \& Linstead, S. (1997) Unpacking Priscilla: Subjectivity and identity in the organization of gendered appearance Human Relations, 50(10), 12751304.

Britton, D. (1997) Gendered organizational logic: policy and practice in men's and women's prisons. Gender \& Society 11(6), 796-818.

Britton, D. (2000) The epistemology of the gendered organization. Gender \& Society, 14(3), 418-434. 
Bryman, A., \& Bell, E. (2007) Business Research Methods. Oxford: Oxford University Press.

Calas, M., \& Smircich, L. (2005) From the 'Woman's Point of View' Ten Years Later: Towards a Feminist Organization Studies In S. Clegg, C. Hardy, T. Lawrence \& W. Nord (eds.), The Sage Handbook of Organization Studies. London: Sage.

Clegg, S. (1981) Organization and Control. Administrative Sciences Quarterly, 26, 532-545.

Cockburn, C. (1985) Machinery of Dominance. London: Pluto Press.

Collinson, D. L., \& Hearn, J. (1994) Naming Men as Men: Implications for Work, Organization and Management. Gender, Work and Organization, 1(1), 2-22.

Daley, R. (1980) An American Saga. Juan Trippe and His Pan Am Empire. New York: Random House.

Dye, K., \& Helms Mills, J. (2005) Making sense of feminist strategies of organizational change. Paper presented at the Academy of Management annual conference., Honolulu.

Ferguson, K. E. (1984) The Feminist Case Against Bureaucracy. Philadelphia, Penn: Temple University Press.

Foucault, M. (1980) The History of Sexuality. Vol. 1. New York: Vintage Books.

Hultin, M., \& Szulkin, R. (2003) Mechanisms of inequality - unequal access to organizational power and the gender wage gap European Sociological Review, 19(2), 143-159.

Josephson, M. (1944) Empire of the Air. New York: Harcourt, Brace and Company.

Kane, P. (1974) Sex objects in the sky. Chicago, Ill.:: Follett.

Lewis, J., \& Morgan, D. H. J. (1994) Gendering organizational change: The case of relate, 1948-1990. Human Relations, 47(6), 641.

Maddock, S. (2002) Modernization requires transformational skills: the need for genderbalanced workforce. Women in Management Review, 17(1), 12-17.

McDowell, L., \& Court, G. (1994) Missing subjects: gender, power, and sexuality in merchant banking. Economic Geography, 70(3), 229-251.

Mills, A. J. (2002) Studying the Gendering of Organizational Culture Over Time: Concerns, Issues and Strategies. Gender, Work and Organization, 9(3), 286-307.

Mills, A. J. (2006) Sex, Strategy and the Stratosphere: The gendering of airline cultures. London: Palgrave Macmillan. 
Mills, A. J., \& Chiaramonte, P. (1991) Organization as Gendered Communication Act. Canadian Journal of Communications,, 16(4), 381-398.

Mills, A. J., Durepos, G., \& Wiebe, E. (2009) Sage Encyclopedia of Case Study Research (Vol. I). Thousand Oaks, CA: Sage.

Mills, A. J., \& Helms Mills, J. (2004) When Plausibility Fails: towards a critical sensemaking approach to resistance. In R. Thomas, A. J. Mills \& J. Helms Mills (eds.), Identity politics at work: Resisting gender and gendered resistance. Londong: Routledge.

Mills, A. J., \& Tancred, P. (eds.). (1992) Gendering Organizational Analysis. Newbury Park, CA.: Sage.

Oakley, A. (2002) Gender on Planet Earth. New York: Blackwell Publishers Ltd.

Olsson, S., \& Walker, R. (2003) Through a gendered lens? Male and female executives' representations of one another Leadership \& Organization Development Journal, 24(7/8), 387-396.

Phillips, N., \& Hardy, C. (2002) Discourse Analysis. Investigating Processes of Social Construction (Vol. 50). Thousand Oaks, CA: Sage.

Prasad, A., \& Mir, R. (2002) Digging Deep for Meaning: A Critical Hermeneutic Analysis of CEO Letters to Shareholders in the Oil Industry. Journal of Business Communication, 39(1), 92-116.

Rindfleish, J., \& Sheridan, A. (2003) No change from within: Senior women managers' response to gendered organizational structures. Women in Management Review, 18(5/6), 299-310.

Rutherford, S. (2001) 'Are you going home already?' - the long hours culture, women managers and patriarchal closure. Time \& Society, 10(2-3), 259-276.

Shafritz, J. M., \& Ott, J. S. (eds.). (1995) Classics of Organization Theory. Scarborough, Ont: Nelson.

Townsley, N. (2003) Review article: Looking back, looking forward. Mapping the gendered theories, voices, and politics of organization. Organization, 10(3), 617-639.

Unger, R. M. (2004) False necessity : anti-necessitarian social theory in the service of radical democracy : from Politics, a work in constructive social theory (Paperback ed.). London ; New York: Verso.

Walters, M. (2005) Feminism: A Very Short Introduction. . Oxford: Oxford University Press.

Weedon, C. (1993) Feminist Practice \& Poststructuralist Theory. Oxford: Blackwell. 
Weick, K. E. (1995) Sensemaking in Organizations. London: Sage.

\section{NOTES}

${ }^{i}$ One citation search, using ISI Web of Knowledge, found 607 references to Acker's gendered substructure in journals published between 1990 and 2006, covering such diverse areas of study as ergonomics, organizational analysis, education, social issues, medicine, and information systems (Lead Author, 2006). In 1995 Acker's (later, 1992) model was deemed a "classic organization theory" in an edited collection not noted for its inclusion of female scholars let alone gender (Shafritz \& Ott, 1995).

ii The Pan American World Airways Collection 341, Series 1 and II, -- consisting of over fifteen hundred boxes of material - is housed at the Otto Richter Library of the University of Miami. Hereafter referred to as the Pan Am Collection.

iii Bender \& Altschul (1982); Daley (1980); and Josephson (1944).

iv This was also confirmed through discussions with Joan Acker (in August, 2006) who, while not necessarily endorsing our entire argument, was supportive of the idea of revisiting ’organizational logic. 